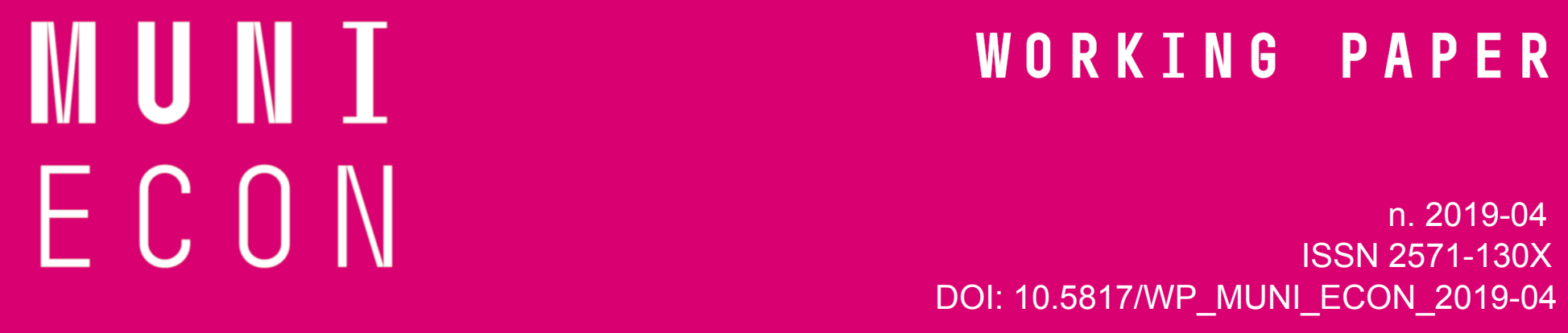

Published in: Journal of Business Ethics, 2020, Article

\title{
The Pied Piper: Prizes, Incentives, and Motivation Crowding-in
}




\section{The Pied Piper: Prizes, Incentives, and Motivation Crowding-in}

\section{Abstract}

In mainstream business and economics, prizes such as the Presidential Medal of Freedom are understood as special types of incentives, with the peculiar features of being awarded in public, and of having largely symbolic value. Informed by both historical considerations and philosophical instances, our study defines fundamental theoretical differences between incentives and prizes. The conceptual factors highlighted by our analytical framework are then tested through a laboratory experiment. The experimental exercise aims to analyze how prizes and incentives impact actual individuals' behavior differently. Our results show that both incentives (monetary and contingent) and prizes (non-monetary and discretional rewards) boost motivation to perform if awarded publicly, but only prizes crowd-in motivation promoting virtuous attitude.

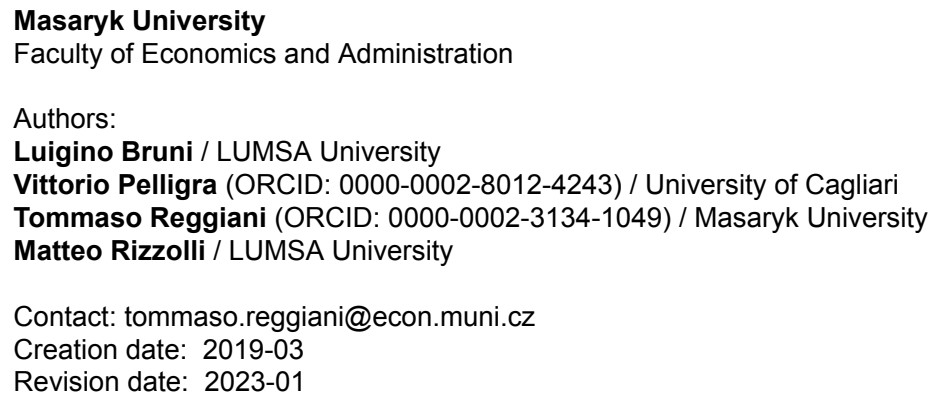




\title{
The Pied Piper: \\ Prizes, Incentives, and Motivation Crowding-in
}

\author{
Luigino Bruni, Vittorio Pelligra, Tommaso Reggiani, Matteo Rizzolli
}

This version: March $10^{\text {th }} 2019$

\begin{abstract}
In mainstream business and economics, prizes such as the Presidential Medal of Freedom are understood as special types of incentives, with the peculiar features of being awarded in public, and of having largely symbolic value. Informed by both historical considerations and philosophical instances, our study defines fundamental theoretical differences between incentives and prizes. The conceptual factors highlighted by our analytical framework are then tested through a laboratory experiment. The experimental exercise aims to analyze how prizes and incentives impact actual individuals' behavior differently. Our results show that both incentives (monetary and contingent) and prizes (non-monetary and discretional rewards) boost motivation to perform if awarded publicly, but only prizes crowd-in motivation promoting virtuous attitude.
\end{abstract}

Keywords: Incentives, prizes, awards, crowding-in, meaning, intrinsic motivation

JEL Codes: B1, D03, J33

\section{Affiliations:}

Luigino Bruni: LUMSA University, Rome, Italy. 1.bruni@lumsa.it

Vittorio Pelligra: University of Cagliari, Cagliari, Italy; CRENoS. pelligra@unica.it

Tommaso Reggiani: Masaryk University, Brno, Czech Republic; IZA. tommaso.reggiani@econ.muni.cz

Matteo Rizzolli: LUMSA University, Rome, Italy. m.rizzolli@lumsa.it 
"It is clear that the reward lies in the action itself, and that the power of the honorable to attract the minds of men is immense: Its beauty floods our minds and sweeps us along, enchanted with wonder at its brilliance and splendor."

(Seneca, De Beneficiis 22.2).

He advanced to the council-table: And, "Please your honors," said he, "I'm able, By means of a secret charm, to draw All creatures living beneath the sun,

That creep or swim or fly or run,

After me so as you never saw!"

(Robert Browning, The Pied Piper of Hamelin 1842)

\section{Introduction and aim}

Human motivation is complex, and the history of cultures shows that people act based on much more than material rewards. Honor, esteem, recognition, shame, and glory have all been (and still are) important drivers of numerous human actions. However, the mainstream economic approach to the study of behavior in markets and organizations has, from the outset, focused on a narrow set of rewards for actions that made social interactions simpler, more predictable, and controllable. In its parlance, all the motivations that drive human action are almost invariably referred to as "incentives"1. Like modern Pied Pipers, numerous economists envision a future where these elements can be engineered to manipulate individual behavior at will; where intrinsically conflicting interests can be bent to serve some determined goals (see among the others, Jensen and Murphy, 1990; Kurland, 1995; Mirrlees, 1999) and much more. Thus, in the mainstream economists' jargon, the word "incentive" has become a catch-all concept that has absorbed, among others, the concept of

\footnotetext{
${ }^{1}$ The "ideology of incentives" (Bruni, 2015) goes well beyond the boundaries of economic relations. Ruth Grant (2011), who conducted the most systematic research on the history and nature of incentives, offers a vivid repertoire of situations in which incentives are applied and how: "express traffic lanes are set aside during rush hour for cars with more than two passengers. A will stipulates that a daughter will inherit only if she agrees to be a stay-at-home mom. West Virginia pays married couples on welfare an extra $\$ 100$ per month, funded by a federal program to promote marriage. [...] Legislators in South Carolina discuss a proposal to reduce prison sentences for prisoners who donate organs. A soup kitchen feeds the homeless only if they attend a church service first. [...] A state legislator suggests paying poor women $\$ 1,000$ to have their tubes tied while others debate making welfare conditional on the use of the Norplant contraceptive device" (p. 1).
} 
"prize" (Grant, 2019; Sugden 2019, Sandel, 2012) and this vague use of the word has percolated to the everyday business parlance. However, the most recent interdisciplinary research in social psychology, business ethics and behavioral economics points out that what prompts people to action is a mix of multiple dimensions. Material and immaterial ones, monetary and symbolic, extrinsic and intrinsic motives. Stretching the semantic space of the "incentive" concept too far, mainstream economics is accountable for an over-simplification of otherwise very distant phenomena. Indeed, this reductionism does not help in understanding what happens in many actual choices in real-world scenarios, which are too different from one another to be captured and predicted by only one (simple) concept $^{2}$.

This paper has two aims. The first is to theoretically distinguish between prizes and incentives as two extremes of a continuum of rewards, which impact individual behavior somewhat differently. In this paper, we use an ideal-type approach and, therefore, we define the characteristics of pure incentives and pure prizes, an ideal polarization that helps to understand the complexities of concrete (and necessarily spurious) motivational tools in organizations. The second goal of the study is to experimentally distinguish the effect exerted by each of these types of rewards on the behavior of individuals in the context of an employer-employees agency relationship.

As opposed to the now standard use of the word, in this paper, we use a narrow definition of incentive, grounded on its original etymology. The epitome of a pure incentive is a material (in general monetary) reward that is based on individual performance and designed around private selfinterest. For example, think of the productivity bonus offered to an employee to perform a task that has no particular meaning for him. Only as an unintentional indirect effect might it yield positive externalities for third parties. Motivation within an incentive scheme is supposed to be purely instrumental and extrinsic (Benabou and Tirole, 2003). Given this narrow definition, it appears self-

\footnotetext{
${ }^{2}$ This is not to neglect that numerous economists are aware of the complexities and tradeoffs between the use of different types of incentives. For example, see Gneezy et al. (2011), Bowles and Polania-Reyes (2012), and Ashraf and Bandiera (2018) for surveys.
} 
evident that prizes can barely be squared into this definition of incentives, as much of the prevailing literature tends to do (see Frey and Gallus, 2017a-b). In fact, we make the case that prizes are a very different matter. An archetypal prize-for example, think of the American Presidential Medal of Freedom - is given discretionally to someone who has intentionally performed a meritorious act that is recognized to be purposeful because, for example, it produces positive externalities for others. It is awarded publicly, and the value of the prize grows with its publicity and the degree of social approval. Social approbation and recognition actually represent the greater part of the value ascribed to the prize. Notwithstanding the awarding of the prize, the behavior is essentially driven by intrinsic motivations (Deci, 1975; Deci and Ryan, 1985). Therefore, for the remainder of the paper, we use the term reward as a generic word to indicate both incentives and prizes. Our taxonomy of rewards distinguishes between prizes and incentives along four dimensions.

The first dimension concerns the monetary content of the reward. On the one hand, incentives typically have a monetary or material nature, and their size is often considered a rough index of their saliency (the larger, the better). On the other hand, prizes are basically non-monetary, and if they also have an extrinsic value (e.g., academic or artistic prizes), the intrinsic or symbolic value hugely outweighs the extrinsic one.

The second dimension concerns the publicity associated with the reward. While incentives are usually handed out privately, prizes are regularly awarded at public ceremonies, and these events are a quintessential aspect of any prize.

The third dimension refers to the degree of discretion in awarding the prize. Incentives are contingent, that is, they are defined ex-ante before the action to be incentivized occurs and often contractually, and therefore their award can be anticipated with certainty or in expected terms. Prizes are awarded for actions, the merit of which can be established only ex-post and, therefore, they envisage some degree of discretion from the side of the awarder and uncertainty on the side of the awardee (Speckbacher, 2013). 
The last of our dimensions concerns the purpose of the task to which prizes and incentives are applied to. A pure incentive in a typical employer-employee contract is designed to align the interests of the employee (the agent in the economic jargon) with those of the employer (the principal $^{3}$ ), with little if no regard to external effects that could be positive, negative, or neutral (Kurland, 1995). Instead, pure prizes reward virtuous and purposeful actions that have intentional positive external effects as for the other individuals, disadvantaged groups, the environment or the common good. In fact, incentives are designed to induce sufficient extrinsic motivation to perform where there is too little or no intrinsic motivation. On the other hand, prizes are awarded to individuals who have achieved outstanding goals out of intrinsic motivation ${ }^{4}$.

These dimensions define a space between the two pure forms of rewards that is populated by a continuum of hybrid forms. For example, sports prizes are either symbolic and public, like pure prizes, but they often are contingent and have monetary value, like pure incentives. Corporate plaques are symbolic, public and discretional, like pure prizes, but are non-purposeful (in as much as they reward employees for their job performance), like pure incentives. Many more forms of hybrid rewards can be obtained by combining the abovementioned dimensions in different ways. Business organizations use such hybrid forms to a great extent, often mixing up incentives and prizes. For example, a career promotion embodies both the features of an incentive and a prize. Wage increments are important to people not only because of their monetary content but also because they have a symbolic value: An increase in salary is often interpreted as a recognition of one's own quality as a worker and person.

\footnotetext{
${ }^{3}$ The agency model is a standard model in economics as well as in political sciences. It captures the strategic interaction in which an agent (employee/politician/CEO) is able to make decisions on behalf of the principal (employer/voter/shareholder).

${ }^{4}$ This can go to the extreme where a prize is not awarded if some extrinsic motivation (even self-image) can be traced. For example, this is the case in the canonization process for sainthood within the Catholic Church. Among the requirements to be proclaimed a saint, the candidate's motivation must be proven to be completely intrinsic. The candidate must have never acted for the purpose of becoming a saint because it would be a sign of the lack of the necessary virtue of humility, and the heroic virtues are the pre-condition to be proclaimed a saint; see the Apostolic Constitution Divinus Perfectionis Magister (January 25, 1983).
} 
Once this taxonomy has been produced, our paper proceeds with an experiment aimed at distinguishing the effect of different forms of rewards on individuals' behavior. Our experimental confirm that prizes and incentives affect motivation in different ways: In particular, we show that prizes crowd-in motivation, as performance in a standard effort task increases after the prize is removed while incentives do not have such an effect.

As stated before, business ethics scholars have long been studying both the complexity of human motivation and the many alternative tools to activate such motivation as well as the sideeffects generated by highly-powered financial incentives within firms and organizations. For instance, McGuire et al. (2003) and Fabrizi et al. (2014) documented a negative association between long term incentive plans and corporate social performance. Notably, the last paper showed a positive effect on CSR scores generated by non-monetary measures. Ims at al. (2014) documented how the practice of relying on increasing levels of financial incentives may have an adverse effect on executives' performance at large. Baucus and Beck-Dudley (2005) provided interesting insights on how the over-reliance on incentives (positive and negative) encourages employees to operate at lowest stages of moral reasoning when confronting ethical dilemmas. From a more philosophical perspective, Kulshreshtha (2005) highlighted the divergence between economic incentives and ethical motives for action in business practice, and he emphasized the pressing need to reduce the divergence between economic incentives and ethical motives for action. Analysing leadership issues in the context of values-based (or poetic/authentic) business organizations, Freeman and Auster (2011) and Auster and Freeman (2013) criticized the extensive use of top-down incentives in organizations and suggested that organizations should commit to having conversations about their values in order to develop an organizational culture that nourishes authenticity. In their exploration of the social, ecological, and existential costs of economic incentives, Shoaib and Baruch (2017) suggested that incentives might boost the apparent performance, but not necessarily the intended performance, raising moral hazard concerns. They showed how employees' affection for incentives impacts their unethical behavior likelihood and conjectured that this relation might be moderated by 
organizational justice perceptions and might be partially mediated by individual expectations generating motivational crowding-out.

The remainder of the paper is organized in the following manner. In section 2, we discuss the concepts of incentives and prizes, and critically review the relevant literature on the topic. In section 3, we describe the experimental design, hypotheses, and procedures. In section 4 , we discuss the results. In Section 5, we provide the conclusion.

\section{On incentives and prizes: Roots and state-of-the-art}

On page 1 of their comprehensive and influential book, The Theory of Incentives, Laffont and Martimort (2002) stated, "how to design institutions that provide good incentives for economic agents has become a central question for economics," In the same vein Levitt and Dubner (2006) boldly claim that "incentives are the cornerstone of modern life" (p. 13) ${ }^{5}$. However, despite the centrality ascribed to "incentives" in mainstream economics and — in general—in modern parlance, neither books provide us with a definition of what incentives actually are. Surprisingly enough, we cannot even find an entry on "incentives" in the New Palgrave Dictionary of Economics or in many other essential reference resources for economists.

However, precisely because of its centrality in economic discourse, the concept of incentive deserves at least a certain degree of clarification. In this respect, an excellent starting point is the book by Grant (2011), who traces the origin of the widespread use of the word in a space and time where the scientific theories of management met behaviorism, which constitutes the psychological science of behavior change. These theories were developed in the United States in the 1930s and then took off around the interwar period, an era characterized by the rise of totalitarianism. This was an era of civil pessimism, similar in certain respects to that in which Machiavelli and Hobbes lived; it is no

\footnotetext{
${ }^{5}$ Other few quoted examples of the incentive ideology are "Incentives are the essence of economics" (Prendergast, 1999, p. 7); "Fame, power, reputation, sex, and love are all important incentives. Economists even think that benevolence responds to incentives" (Cowen and Tabarrok, 2015, p. 2); "The basic 'law' of behavior is that higher incentives will lead to more effort and higher performance" (Gneezy et al., 2011, p. 1).
} 
surprise that such theories, based on pessimistic and parsimonious thinking about human nature, were developed at that time. The logic of incentives was first received with significant controversy and heated ethical debates, which, however, soon fell silent (Grant, 2011). During the rise of communism and the Cold War, the Western approach to controlling people's productivity by means of incentives appeared to be the lesser of two evils; control and planning within organizations were the small doses of poison necessary to vaccinate Western societies against the possibly deadly virus of central planning and totalitarian coercion.

The etymology of the word "incentives" betrays these manipulative pre-modern origins. The Latin root of the word incentivus (from incinere) refers to the act of singing and enchanting. Its current, more familiar meaning of stimulus and spur comes from the fact that musical instruments, called incentivus, such as flutes or pitch pipes used to tune choirs and orchestra were also used to dictate the running pace for soldiers in battle (Pianigiani, 1990) ${ }^{6}$. In time, the word came to live outside the battlefield, signifying any instrument that could spur individuals on, make them eager, or urge them to bold action. Thus, it is no coincidence that the character of the legend of the Pied Piper of Hamelin, that gives this paper its title, uses a flute to lead rats and then children to their doom. The incentivus galvanized soldiers, rats, and children, inducing them to go where their pied pipers wanted them to be; thus, the incentive redirected individuals' action toward the goals set by their principal.

The word "prize" also deserves some explanation. We preferred this word over the close synonym "award" that appears in a number of recent studies (see Frey and Gallus, 2017b, for a survey) because it is a closer translation of the original eighteenth-century Italian word "premio" ${ }^{\text {"7 }}$ To explain this

\footnotetext{
${ }^{6}$ See also Giuseppe Manno (1831): "Since in Latin incentivus, whether applied to aerophones, such as flutes or trumpets, signified the sound (incentivum) of those instruments, it was later employed to express those aforementioned incitements and provocations. At that time, one intrepid orator came to realize that, being that man was as aroused by the voice of passion as soldiers were by the sound of trumpets, the transposition of tuba incentiva from the battlefield to humans' hearts was a mere transliteration of a comparison into a metaphor."

${ }^{7}$ Among its different meanings, the word "praemium" in classical Latin also mean reward, prize, recompense, gift (Cicero spoke of honores et praemia bene de re publica meritorum et merentium). The Latin-German dictionary by Georges (1998) specifies that this third meaning of praemium is intended as the opposite of "punishment." A particular contractual dimension appears to be implied by the concept of prize; the medieval-patristic dictionary by Blaise and Chirat (1954) reports two meanings of the word praemium: i) recompense, reward and ii) gift, benefit (of redemption).
} 
choice, we direct the reader to one of the most influential books in the history of ideas, Cesare Beccaria's On Crimes and Punishments (1764), which first grounded public policy, and particularly criminal law, in a proto-utilitarian framework that considers punishment merely as a negative incentive. Two years later, a lesser-known book, On Virtues and Prizes, was published by Giacinto Dragonetti, a student of the Neapolitan economist Antonio Genovesi the founder of the tradition of civil economy (see Bruni and Sugden, 2000, 2008; Bruni and Zamagni, 2016). Dragonetti was convinced that exclusively concentrating on punishment, as the work of Beccaria seemed to imply, would not be sufficient to get the Kingdom of Naples back on a path of civil and economic growth and out of feudalism (Bruni, 2013; Bruni and Sugden, 2013). In the introduction of his book, Dragonetti stated, "We have made numberless laws to punish crimes, and no one is established to reward virtue" (1769, p. 13). On this basis, he elaborated his idea of "premial law," where virtuous behavior would be rewarded as opposed to bad behavior being punished. Dragonetti's idea of a prize is not merely the flip side of Beccaria's negative incentive. In this classical tradition, that traces back to Aquinas, prizes are acknowledgments of intrinsically good activities that are not perceived as an expected counteraction within a reciprocal or contractual relationship, where recompenses are established ex-ante. Receiving a prize is generally neither the only final goal nor the sole motivation for the person performing a given virtuous activity. Even when this activity is known to possibly be associated with receiving an award, it represents a form of acknowledgment and a signal of appreciation of the value of certain conducts or actions. Prizes, with their symbolic values, convey meaning on what ought to be done and thus shape the intrinsic motivation of individuals in a way that incentives cannot achieve, as incentives shape behavior via extrinsic motivation. In other words, prizes have an expressive function as they unequivocally inform beliefs about desirable conduct (see also Sunstein, 1996; Benabou and Tirole, 2012; McAdams, 2015; Nadler 2017 and the literature on the expressive function of the law).

This rather lengthy historical perspective on incentives and prizes sets a wider scenario for the literature review that follows. Our paper crosses several streams of literature dealing with rewards 
and their impact on human motivation. Here, we will briefly mention the ones that are more related to our experimental study.

\subsection{Intrinsic and extrinsic motivation.}

Edward Deci and Richard Ryan, in particular, pioneered the study of the relationship between intrinsic and extrinsic motivation in the context of their self-determination theory (Deci, 1971, 1975; Deci and Ryan, 1985). The basic idea is that individuals within organizations accomplish tasks influenced by two types of motivations: On the one hand they are motivated by the intrinsic goals of their work and activities; on the other hand, they are motivated by the rewards the organization offers in exchange of their effort. Thus, for example, the physician's goals may include both the insurance bill and the health of her patients, while the teacher's goal may include both the salary and the education of his students. Intrinsic motivation is often assumed to lead to better performance in certain kinds of jobs, to be particularly salient among a subset of the population, and to be directly unobservable by employers. Crucially, intrinsic motivation is interpreted as the willingness to forgo external rewards in pursuit of the internal goals of one's work.

From a sociological standpoint, Titmuss (1970) introduced the idea that monetary incentives could undermine even blood donations, as they substituted intrinsic motivation with monetary incentives. Frey and Oberholzer-Gee (1997), Frey and Jegan (2001), and Gneezy and Rustichini (2001a, 2001b) popularized the crowding-out hypothesis among mainstream economists. The interactions between these two streams of literature of psychologists and economists are reviewed in Festré and Garrouste (2015). Benabou and Tirole (2003, 2006) developed an "agency model" and further experimental tests of the crowding-out hypothesis have been surveyed by Bowles and PolaniaReyes (2012), and the once unanimous enthusiasm for incentives and performance-related pay, still displayed in standard economics textbooks, is, at last, making some room for circumstantiated criticism (see Ellingsen and Johannesson, 2007; Gneezy et al., 2011; Frye, 2017). These strands of literature are relevant to our paper in as much as both prizes and incentives are forms of extrinsic 
rewards that may interact with intrinsic ones and thus create crowding-out or crowding-in effects. In particular, our original contribution in this respect concerns the study of the crowding-in effect of prizes.

\subsection{Purposeful mission and meaning.}

Individuals are also prompted to act because of the perceived purposefulness of the activity, even in the absence of rewards. In a controlled experiment, Ariely, Kamenica, and Prelec (2008) showed that subjects building LEGO projects are more motivated ${ }^{8}$ if their project is not disassembled immediately after its completion (thereby implying that it holds some meaning for the experimenter). Further, Kosfeld, Neckermann, and Yang (2014) ran a field experiment where workers have to enter data for either a "very important" goal or for a job that "has already been done." They vary the rewards, offering either a flat wage, a piece-rate monetary incentive, or a symbolic prize. They show that, on average, meaning increases performance by $14 \%$, an effect that is higher than the one of monetary incentives $(8 \%)$ but lower than the one of prizes (19\%). Interestingly, prizes and purposefulness appear to be substitutes, as their interaction does not further improve performance. A third relevant study is by Chandler and Kapelner (2013), who ran an experiment where three treatments were considered. In the "meaningful condition," the subjects were told that their task might be useful for scientific research; in the "zero context condition," they were told that their job could be used in a scientific research; finally, in the "shredded condition," the subjects were told that their work was of no interest. The "meaningful treatment" had -not surprisingly- the highest degree of participation. Finally, the effect of purposefulness on motivation can also be captured by other-regarding theories of behavior, such as the theory of warm-glow giving (Andreoni, 1990). With respect to this literature, our experiment fully disentangles the interactions between prizes and incentives in the presence of purposeful tasks.

\footnotetext{
${ }^{8}$ They are willing to accept to perform the task for a less generous remuneration.
} 


\subsection{Public and self-image concerns.}

Incentives also affect motivation, trough image concerns which is "the desire to be liked and respected by others and by one's self' (Ariely et al., 2009, p. 544). Bénabou's and Tirole's (2006) showed that, in the presence of image concerns, motivation to engage in prosocial activities could be crowded-out if the presence of monetary incentives might induce people to think that behavior is driven by extrinsic instead of intrinsic motivation. In two experiments, Ariely et al. (2009) provided evidentiary support for this image crowding-out effect of monetary incentives, thereby showing that monetary incentives and publicity interact negatively when the activity is prosocial, which supports the hypothesis that image motivation is subject to being crowded-out. Lacetera and Macis (2010) analyzed data of an entire town population of blood donors that were rewarded with symbolic medals and showed that donations increase only when medals are announced publicly through the newspaper and awarded in public ceremonies. The authors concluded that social image concerns are a powerful driver of motivation in this context. Moreover, in our set-up, the public dimension is an important component that distinguishes incentives from prizes. If social image concerns are at work, they could impact the efficacy of prizes in an ambiguous manner. The public dimension of the reward is the natural connection to the next relevant stream of literature related to our paper.

\subsection{Awards and recognition.}

Frey $(2006,2007,2015)$ also provided important contributions to the stream of literature on awards (prizes in our jargon), recently surveyed in Frey and Galus (2017a, 2017b). This largely descriptive literature seems to consider prizes a special subset of incentives (Adam and Hicks, 2000; Frey, 2006; Mathauer and Imhoff, 2006; Neckermann and Frey, 2013). Take the case of Kosfeld and Neckermann (2011), who characterized awards as simply incentives that are awarded in public through a tournament. An eloquent expression of this reductionism can be found in Footnote 1 of the paper, where the authors define the piece-rate system of "sales awards" in commercial business as an example of prizes. In our approach, "sales awards" are hybrid forms of rewards that are somewhat 
closer to incentives than prizes (monetary and non-purposeful). Ashraf et al. (2014) employed a field experiment where they disentangled social comparison from the award itself and show that, while social comparison has a negative impact on performance, awards have a positive effect. Moreover, the importance of public ceremonies is also highlighted in the growing literature on status and recognition (see Weiss and Fershtman, 1998; Ellingsen and Johannesson, 2007; Moldovanu et al., 2007) that links motivation to the individual quest for identity (Akerlof and Kranton, 2005).

\subsection{Non-pecuniary rewards.}

A number of papers deal specifically with the impact of non-pecuniary rewards on performance (Falk, 2007; Maréchal and Thöni, 2016; Neckerman and Yang, 2017). Levitt et al. (2016) found that for students (grades 2 to 5), a symbolic award (a trophy or a wall photo) costing approximately $\$ 3$ has the same impact on their scores as a financial incentive of up to $\$ 20$. Kube et al. (2012) show that the nature of the reward (monetary vs. symbolic) strongly impacts gift exchange and, thus, performance. For example, agents reciprocate the principal's gift of a bottle worth $€ 7$ by increasing their productivity by $25 \%$, while their performance remains the same when the principal provides a cash gift of $€ 7$. The gift exchange remains strong even in a third treatment when the price of the bottle is revealed to agents, thereby eliminating the potential effects of biased beliefs.

Our paper is also closely related to the work of Bellé (2015); in a field experiment in the study, nurses were alternatively rewarded with either baseline pay, baseline pay and a performance-related incentive (gift card), or baseline pay and a prize (a certificate for outstanding contribution). Further, the nurses were randomly assigned to either an open condition (individual performance displayed on a bulletin board) or a secret condition (performance discussed privately). The purposefulness of their job was emphasized further in a treatment where the nurses had the opportunity to meet a person who benefitted from their job. Overall, monetary incentives performed poorly when they were made public, thereby revealing a negative interaction between incentives and publicity—particularly when 
such incentives heightened their perception of making a positive difference in other people's lives. We now proceed with the illustration of our experimental design.

\section{Experimental design, hypotheses, and procedures}

Eleven subjects participated in each experimental session; ten took the role of employees and one took on the role of the employer. In the experiment, they were respectively named role $A$ and role $P$. Employees had to perform a real effort task along the lines of that in Gill and Prowse (2012), which consisted of correctly placing as many sliders as possible ${ }^{9}$ on a pre-assigned number (see Figure 9 in the Appendix) within a five-minute period. Employees who correctly placed sliders were paid 10 Experimental Currency Units (ECU 200=€1) per piece. These ECUs accumulated in each individual's personal account. The employer observed the employees' performance and collected a percentage of each employee's payment -1 ECU for each correctly placed slider. Each employer gained $1 / 10^{\text {th }}$ of the gains for each of her 10 employees, or in other words, the average gains in the piece-rate task of the ten employees.

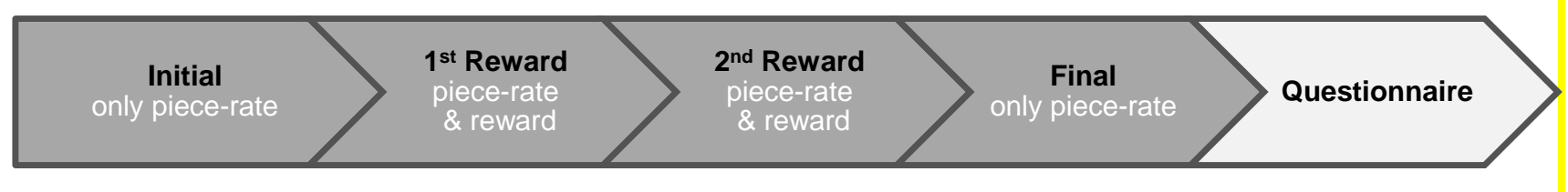

Figure 1. Flowchart of the experimental phases

The experiment was divided into four phases of five minutes each, followed by a fifth questionnaire phase. In each phase, the subjects assigned to the employee's role had to perform the effort task described above. The Initial and Final phases were exclusively remunerated using piece-rate payments. In the two central Reward phases, the subjects also participated in a tournament in which the three subjects with the highest number of correctly placed sliders received a reward. This structure was constant across treatments.

\footnotetext{
${ }^{9}$ This is a fairly standard task used in lab experiments. For a discussion see also Erkal et al. (2018). For a discussion of the use of lab experiments to understand issues related to effort and labor see Charness and Kuhn (2011).
} 
The experiment was conducted both in Cagliari and Cologne; 308 subjects were recruited via ORSEE (Greiner, 2015). The experiment was programmed in Z-Tree (Fischbacher, 2007). The average payment was $€ 14$, and the experiment lasted approximately 50 minutes.

\subsection{Treatment variations}

We had four main Self-interested treatments, reflecting a $2 \times 2$ design, plus two additional Purposeful treatments, as in Figure 2. The main Self-interested treatments' variations always affected the rewards assigned in the two central ( $1^{\text {st }}$ and $2^{\text {nd }}$ Reward) phases. These variations concerned, on one the hand, whether the reward was more Incentive-like (Monetary \& Contingent) or more Prize-like (Nonmonetary \& Discretional) and, on one other hand, the degree of Publicity of the award ceremony.

\begin{tabular}{|c|l|c|}
\hline & Self-interested & Purposeful \\
\hline Incentive \& Private & T1: 66 subjects & T5: 22 subjects \\
\hline Incentive \& Public & T2: 66 subjects & \\
\hline Prize \& Private & T3: 66 subjects & \\
\hline Prize \& Public & T4: 66 subjects & T6: 22 subjects \\
\hline
\end{tabular}

Figure 2: Matrix of our experimental treatments. Note that $\mathrm{T} 1$ is the Pure Incentive Treatment (Self-interested, Monetary \& Contingent, Private), whereas T6 is the Pure Prize treatment (Purposeful, Non-Monetary \& Discretional, Public)

In our Incentive-like treatments (T1, T2 but also T5) we always combined two characteristics: The reward was both monetary (a payment of $€ 10$ ) and contingent (always awarded to the three best performers). In our Prize-like treatments instead (T3, T4 and also T6) the rewards were both nonmonetary (a university coffee mug in T3 and T4) and discretionary (the employer could decide not to award the prize). Indeed no employer in the prize treatments made use of this discretional power, and all prizes were eventually awarded.

The other treatment dimension in the four main self-interested treatments concerned the degree of publicity; indeed the reward could either be delivered privately by direct communication with the winning subjects via a computer screen (in T1 and T3), or be provided publicly during a public 
awarding ceremony in front of the other players (in T2 and T4). In this case, the three subjects were asked to step forward in the lab, where they received the prize and were cheered on by the rest of the subjects.

We also tested two further treatments in which we added a degree of purposefulness to the effort task. In the four main Self-interested treatments (T1, T2, T3 and T4), the employer was the subject who enlisted first for the experiment and received one ECU for each ten ECU produced by every employee, while in the two purposeful treatments (T5, T6) the employer was a student's representative of the Red Cross and his or her gains were all eventually devolved to the charity.

\subsection{Some critical thoughts on our experimental design.}

As with any experiment, the design choices include some excruciating trade-offs and a few inherent limitations of the lab approach. Some of these critical issues are discussed in the following paragraphs.

Our treatment manipulations. In order to fully explore our taxonomy of rewards, some $2^{4}$ treatments would have been needed. Indeed, some characteristics of incentives and prizes are so inextricably linked that we opted for keeping them combined (incentives are always monetary \& contingent while prizes arere always non-monetary and discretional) while some other combinations were simply not tested (we only had two treatments with purposeful tasks).

The symbolic meaning of the prize. One may argue that our prize, a university coffee mug, may not be salient in terms of monetary value or may not be sufficiently symbolic. In fact, we chose to use the university coffee mug for the same reasons for which it has become a common tool in several experiments measuring the endowment effect (see, for example, Kahneman et al., 1990; or Ward, and Broniarczyk, 2011), that it is an object of some use to most people, and many students happen to know its approximate value because it sells well at university shops. At the same time, for a majority of the students, it symbolizes one's belonging to the university community and thus has a marked symbolic meaning. The use of monetary and non-monetary rewards in lab experiments is 
discussed by Read (2005). In fact, even monetary rewards can have symbolic meaning (Mickel and Barron, 2008). As in Kube et al. (2012), we selected a non-monetary gift that had approximately the same monetary value as that of the incentive ( $€ 9$ and $€ 10$ respectively).

The publicity of the ceremony. The ceremony confers three prizes in front of a seven-person audience. Admittedly, this is not a large crowd to cheer the recipients. Nevertheless, it is intrinsically different from the private and anonymous transmission of this information to the participants. Further, similar group sizes are used in other experiments that address with the effect of publicity, such as in Bradler et al. (2016).

The purposefulness of the task and the role of the employer. In the additional purposeful treatments, all the employer's gains, equivalent to the average employees' gains for the piece rate task, were eventually donated to the Red Cross. We selected this specific charity because we ran this experimental variation at the University of Cologne and, in the German context, the Red Cross is a very popular charitable organization. Other research projects using German subjects donate to the Red Cross for similar reasons (see, for example, Doerrenberg and Duncan, 2014 but also Ariely at al., 2009 with US subjects).

The small symbolic value of the prize, the small size of the group attending the ceremony and the mandatory donation of the prize to the charity are all arguments that work against the possibility of observing any meaningful difference between treatments along the several dimensions highlighted above. Therefore, any observed difference indicates the relevance of these dimensions in explaining individual behavior in the shadow of different rewarding mechanisms.

\subsection{Theoretical predictions}

Based on the literature reviewed and our sketched theory of rewards, we offer some theoretical predictions.

Do rewards matter after all? The mainstream approach treats incentives and prizes alike and predicts them to have the same impact on productivity. In our experiment, both types of rewards are 
introduced in the central two phases and withdrew in the Final phase. We thus put forward the following predictions:

Prediction 1. Ho: When rewards in the $1^{\text {st }}$ Reward phase are introduced, motivation increases in all treatments.

Prediction 2. Ho: When rewards in the Final phase are withdrawn, motivation decreases in all treatments.

Does the monetary incentive crowd-out motivation? It has been shown that in many circumstances, monetary incentives crowd-out motivation to perform, and if this is the case, then they have persisting (adverse) effects even when they are withdrawn (see the literature review). Is this the case in this experiment as well?

Prediction 3. $H_{0}$ : When incentives (monetary \& contingent) are introduced in the $1^{\text {st }}$ Reward phase, motivation and performance decrease in treatments T1, T2, and T5.

Prediction 4. Ho: When incentives (monetary \& contingent) are withdrawn in the Final phase, motivation remains low.

Little is known about the crowding-out effects of prizes. Taking the prizes-as-incentives reductionism seriously, we put forward the following mirroring predictions:

Prediction 5. Ho: When prizes (non-monetary \& discretional) are introduced in the $1^{\text {st }}$ Reward phase, motivation decreases in treatments T3, T4, and T6

Prediction 6. $H_{0}$ : When prizes (non-monetary \& discretional) are withdrawn in the Final phase, motivation remains low.

Notably, Predictions 3 and 5 are in contrast to Prediction 1, and Predictions 4 and 6 are in contrast to Prediction 2.

Does publicity increase performance? Public recognition is often considered an additional positive payoff to be given on top of the reward, and as such should unequivocally boost motivation further. 
However, Benabou and Tirole's $(2003,2006)$ work on image concerns indicates a potentially countervailing effect of publicity that may nullify or even negatively impact motivation and thus performance.

Prediction 7. Ho: When rewards are made public (T2, T4, and T6), performance increases.

Does purposefulness increase performance? The results of previous experiments show that purposefulness is very important for human motivation; however, Kosfeld, Neckermann, and Yang (2014) show that meaning may be a substitute for prizes. In our experimental design, treatments T5 and T6 produced positive spillovers for a charity in addition to the rewards for the individual. Therefore, we put forward the following prediction.

Prediction 8. Ho: When rewards are purposeful (T5 and T6), performance further increases.

We now measure our predictions against the data obtained from the experiment.

\section{Results}

We begin this section with some descriptive statistics for our subject sample. A total of 264 subjects participated in our four main Self-interested treatments (T1, T2, T3, and T4), and 44 more participated in the additional Purposeful treatments (see Figure 2). In each of the four main treatments, we had six groups of ten employees and one employer. Males constituted $44 \%$ of the sample, and the average age was 23.5 years for women and 25.2 years for males ${ }^{10}$. Half of all the main Self-interested treatments (for a total of 132 subjects) were run at the University of Cagliari economics lab, while the other half (132 subjects) and all purposeful treatments (44 subjects) were run at the University of Cologne economics lab. From now on, the observations concerning employers are discarded, as we focus on employees' effort provision; thus, there are a total of 280 observations.

\footnotetext{
${ }^{10}$ Three subjects (all women) who stated that they were over 45 years of age were excluded.
} 


\subsection{Performance in main Self-interested treatments}

Figure 3 illustrates how average absolute performance changes across both treatments and phases. First, note that, in all treatments, the performance in the last three phases is always larger than in the Initial phase, and that this may incorporate some learning effects ${ }^{11}$. The introduction of both Private Incentives (T1), Public Prizes (T4), and their hybrid forms (T2 and T3) increase the subjects' productivity in both Reward phases. Furthermore, note that performance in the $2^{\text {nd }}$ Reward phase is always larger than in the $1^{\text {st }}$ Reward phase in all treatments. However, some differences in the Final phase are more relevant. On the one hand, performance further increases in the presence of Prizes (T3 and T4), while it reduces in the presence of Incentives (T1 and T2). On the other hand, productivity in the Final phase, when both rewards are withdrawn, never drops below the productivity level in the $1^{\text {st }}$ Reward phase.

Table 1 reports the mean values of the absolute performances in the four phases for the four main experimental conditions. In each cell, the first line reports the average level of productivity in each given phase, as well as, the level of statistical significance of the difference when it is contrasted against the average performance in the Initial phase. The second number represents the percentage variation with respect to the previous phase and whether the changes from previous phases are statistically significant.

\footnotetext{
${ }^{11}$ Admittedly, we do not have a good way to control for learning, as this would require additional treatments with no rewards introduced or withdrawn in any phase.
} 


\section{Private}

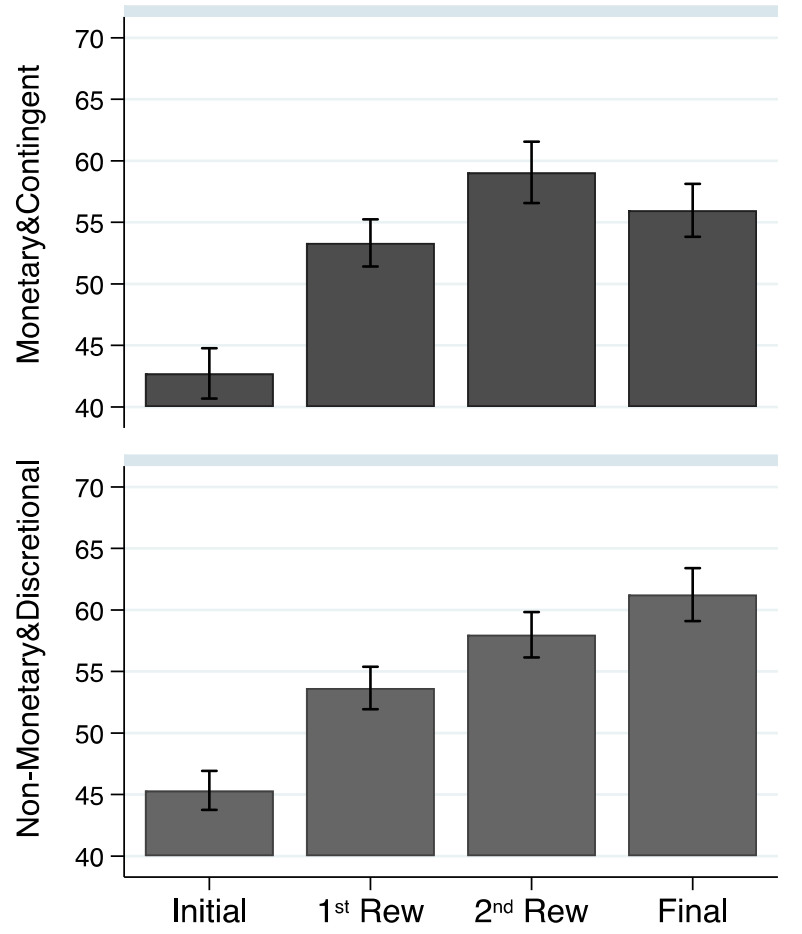

\section{Public}

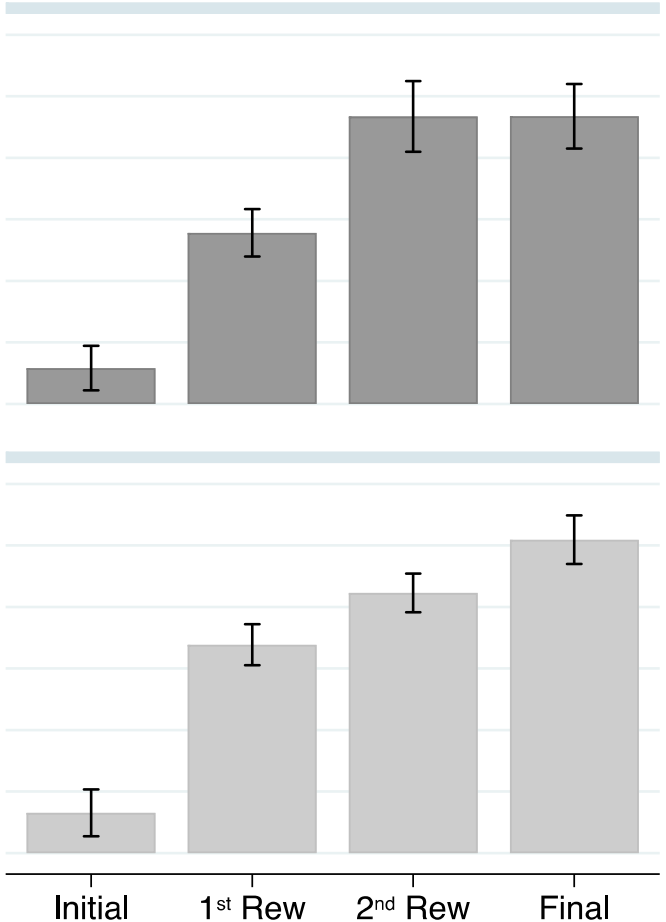

Figure 3: Average absolute performance in all four phases for the four main treatments

Table 1: Average levels of productivity (by conditions and phases)

\begin{tabular}{|c|c|c|c|c|c|c|c|}
\hline \multicolumn{4}{|c|}{ Incentive \& Private } & \multicolumn{4}{|c|}{ Incentive \& Public } \\
\hline Initial & $1^{\text {st }}$ Reward & $2^{\text {nd }}$ Reward & Final & Initial & $1^{\text {st }}$ Reward & $2^{\text {nd }}$ Reward & Final \\
\hline 42.73 & $\begin{array}{c}53.33 * * * \\
+24.81 \% \text { *** }\end{array}$ & $\begin{array}{l}59.06 * * * \\
+10.74 \%\end{array}$ & $\begin{array}{c}55.98 * * * \\
-5.22 \%\end{array}$ & 42.91 & $\begin{array}{c}53.9 * * * \\
+25.61 \% * * *\end{array}$ & $\begin{array}{c}63.37 * * * \\
+17.57 \% * *\end{array}$ & $\begin{array}{c}63.38^{* * *} \\
-0.02 \%\end{array}$ \\
\hline \multicolumn{4}{|c|}{ Prize \& Private } & \multicolumn{4}{|c|}{ Prize \& Public } \\
\hline Initial & $1^{\text {st }}$ Reward & $2^{\text {nd }}$ Reward & Final & Initial & $1^{\text {st }}$ Reward & $2^{\text {nd }}$ Reward & Final \\
\hline 45.33 & $\begin{array}{c}53.66 * * * \\
+18.38 \% * * *\end{array}$ & $\begin{array}{c}58 * * * \\
+8.09 \% * *\end{array}$ & $\begin{array}{c}61.25 * * * \\
+5.60 \%\end{array}$ & 43.28 & $\begin{array}{c}56.93 * * * \\
+31.54 \% * * *\end{array}$ & $\begin{array}{l}61.15 * * * \\
+7.41 * \%\end{array}$ & $\begin{array}{c}65.46 * * * \\
+7.05 \%\end{array}$ \\
\hline
\end{tabular}

Table 1: For each phase in each treatment, the first line reports the average level of productivity. The second number represents the percentage variation with respect to the previous phase. Statistical significance has been calculated using a Wilcoxon rank-sum test: $* * *$ p-value $<0.001 ; * *$ p-value $<0.005 ; *$ p-value $<0.01$. 
Table 2: Multilevel mixed effects regressions. Outcome: Relative effort

\begin{tabular}{|c|c|c|c|c|c|c|}
\hline Outcome: relative effort & (1) & (2) & (3) & (4) & $(5)$ & (6) \\
\hline \multirow[t]{2}{*}{ Public Ceremony } & $0.143 * *$ & $0.143 * * *$ & $0.138 * *$ & $0.138 * *$ & $0.116^{* *}$ & $0.095^{*}$ \\
\hline & $(0.06)$ & $(0.05)$ & $(0.05)$ & $(0.05)$ & $(0.06)$ & $(0.06)$ \\
\hline \multirow[t]{2}{*}{ Prize (Non-mon.\&Discretional) } & 0.009 & 0.009 & 0.011 & 0.011 & -0.01 & -0.017 \\
\hline & $(0.06)$ & $(0.05)$ & $(0.05)$ & $(0.05)$ & -0.06 & $(0.06)$ \\
\hline \multirow[t]{2}{*}{ Purposeful } & & -0.069 & -0.088 & -0.088 & -0.099 & -0.083 \\
\hline & & $(0.08)$ & $(0.08)$ & $(0.08)$ & $(0.08)$ & $(0.08)$ \\
\hline \multirow[t]{2}{*}{ Lab: Cagliari } & & 0.065 & 0.079 & 0.079 & 0.079 & 0.078 \\
\hline & & $(0.06)$ & $(0.06)$ & $(0.06)$ & $(0.06)$ & $(0.06)$ \\
\hline \multirow[t]{2}{*}{ Gender: male } & & & -0.068 & -0.068 & -0.068 & -0.068 \\
\hline & & & $(0.05)$ & $(0.05)$ & $(0.05)$ & $(0.05)$ \\
\hline \multirow[t]{2}{*}{ Age } & & & $-0.013 * *$ & $-0.013 * *$ & $-0.013 * *$ & $-0.013^{* *}$ \\
\hline & & & $(0.01)$ & $(0.01)$ & $(0.01)$ & $(0.01)$ \\
\hline \multirow[t]{2}{*}{$1^{\text {st }}$ Reward phase } & & & & $0.286^{* * *}$ & $0.286^{* * *}$ & $0.286 * * *$ \\
\hline & & & & $(0.03)$ & $(0.03)$ & $(0.03)$ \\
\hline \multirow[t]{2}{*}{$2^{\text {nd }}$ Reward phase } & & & & $0.431 * * *$ & $0.431 * * *$ & $0.431 * * *$ \\
\hline & & & & $(0.03)$ & $(0.03)$ & $(0.03)$ \\
\hline \multirow[t]{2}{*}{ Final phase } & & & & $0.459 * * *$ & $0.410 * * *$ & $0.301 * * *$ \\
\hline & & & & $(0.03)$ & $(0.03)$ & $(0.05)$ \\
\hline \multirow[t]{2}{*}{ Final phase*PUB*Prize } & & & & & $0.170 * * *$ & 0.076 \\
\hline & & & & & $(0.05)$ & $(0.09)$ \\
\hline \multirow[t]{2}{*}{ Final phase*PUB } & & & & & & $0.207 * * *$ \\
\hline & & & & & & $(0.06)$ \\
\hline \multirow[t]{2}{*}{ Final phase*Prize } & & & & & & $0.150^{* *}$ \\
\hline & & & & & & $(0.06)$ \\
\hline \multirow[t]{2}{*}{ Constant } & $1.217 * * *$ & $1.200 * * *$ & $1.555 * * *$ & $1.261 * * *$ & $1.287 * * *$ & $1.295^{* * *}$ \\
\hline & $(0.05)$ & $(0.05)$ & $(0.16)$ & $(0.16)$ & $(0.16)$ & $(0.16)$ \\
\hline Obs. & 1088 & 1088 & 1088 & 1088 & 1088 & 1088 \\
\hline
\end{tabular}

Note: Multilevel mixed-effects linear regression analysis of main treatment effects. This table reports coefficient estimates (standard errors in parentheses) from two-way linear random effects models, accounting for both potential individual dependencies over periods and within-group dependencies.

Significance levels: $* * * \mathrm{p}<0.01, * * \mathrm{p}<0.05, * \mathrm{p}<0.1$ 
Table 2 presents the parametric analysis: We implemented a multilevel mixed effect linear regression analysis to account both for individual (272 subjects) and intra-group dependencies (28 clusters). In this regression, we pooled together experimental sessions conducted in Cologne and Cagliari, controlling for lab-specific effects (dummy variable "Lab: Cagliari"). We found no significant productivity differences in the two different venues. The same consideration holds for the two alternative roles of the employer (Self-interested vs. Purposeful). Performance is here measured in relative terms as individuals' performances have been normalized in the two Reward phases and in the Final phase by the performance in the Initial phase. We excluded 11 subjects who counted less than 11 sliders because any normalization of their subsequent performance would have produced anomalous outliers. An inspection of Tables 1 and 2 leads us to formulate the following results. To begin with, let us indicate that Prediction 1 (productivity increases in the $1^{s t}$ Reward phase, irrespective of the type of reward used) is confirmed while Predictions 3 and 5 (the introduction of incentives and prizes in the $1^{\text {st }}$ Reward phase crowd-out motivation to perform) are rejected. In other words, the conventional idea that any type of reward increases performance is confirmed, and it is not displaced by any crowding-out effect on motivation. Notice that the same conventional theory would predict motivation to fade once the rewards are withdrawn (Prediction 2). However, a marked difference between the Incentive-like vs. Prize-like treatments emerges in the Final phase. In fact, after incentives are withdrawn, performance in the Final phase scales back to more or less the same level as in the $1^{\text {st }}$ Reward phase. However, when prizes are withdrawn, performance in the Final phase actually increases. Note that Prediction 4 (after the incentive is removed, motivation remains crowded-out) fails miserably, as motivation first goes up when incentives are present and then goes down when they are excluded. Prediction 6 (after the prize is removed, motivation remains crowdedout) is somehow turned upside down, as performance increases when the prizes are introduced and then increases even further when the prizes are withdrawn. Indeed prizes crowd-in motivation to perform with high productivity, even in the Final phase when the prize is not awarded. This leads us to formulate our first noticeable result, which is described below: 


\section{Result 1. Prizes crowd-in motivation, incentives do not.}

Estimates form parametric analysis (model 6 of Table 2) show that public prizes induce individuals to increase their productivity by $15 \%$ in the Final phase, as compared to the other spurious treatments. While it is inappropriate to discuss the crowding-out effects of incentives in the Final phase (because, in fact, productivity never drops below the initial level of the Initial phase), there definitely exists a crowding-in effect of prizes, both public and private.

We also verify whether Prediction 7 (public rewards, ceteris paribus, increase motivation) is supported in our experimental results. Indeed, the average performances of public treatments (the right-hand graphs in Figure 3) are visually higher than those of private treatments. This is in line with the literature on self-image concerns (Benabou and Tirole, 2006; Tonin and Vlassopoulos, 2013). It turns out that the public dimension of the reward shifts effort upward, in general, as measured by the average number of correctly placed sliders across the last three phases with respect to the Initial phase. The average effort is 1.206 in private treatments against 1.323 in public ones. An examination of models (1-6) in Table 2 suggests the strong effect of public treatments in aggregate, and an examination of model 6 suggests that this effect is particularly pronounced in the Final phase (+20\% This leads us to formulate our second result:

\section{Result 2: Public ceremonies, ceteris paribus, improve performance.}

\subsection{Comparing Self-Interested and Purposeful treatments}

We now extend our analysis to consider the Purposeful treatments for which we have fewer observations and only from our sessions in Cologne. For this reason, we exclude all observations collected in Cagliari. In these two additional treatments (22 subjects each), we replicated the Private Incentive (T1) and Public Prize (T4) treatments. 


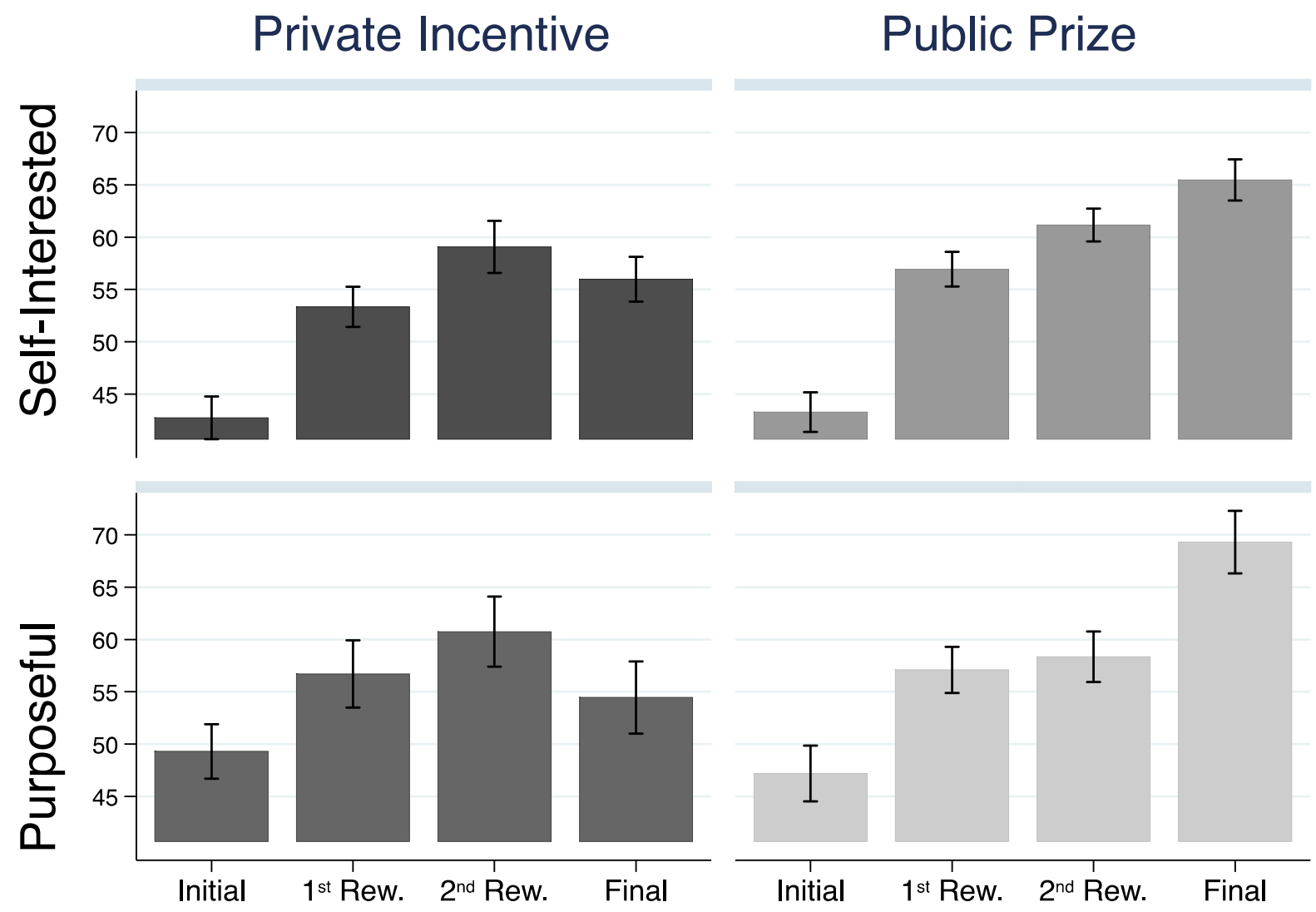

Figure 4: The figure compares the average absolute performance in the four phases between the main Self-interested treatments (T1 and T4) and the Purposeful treatments (T5 and T6).

In the upper two graphs of Figure 4, the results of T1 and T4 replicate those already seen in Figure 3. The two graphs below depict the results for the two additional purposeful treatments (T5 and T6). The average effort exerted by subjects is greater in the Purposeful treatments than in the Selfinterested treatments (56.64 vs. 54.72), and the two distributions are statistically different according to the Wilcoxon rank-sum test $(p$-value $=0.09)$ and the Kolmogorov-Smirnov test ( $p$-value $=0.05)$. This statistically significant effect in the non-parametric tests is obtained despite the small number of observations in our two additional treatments. This leads us to formulate our third result:

\section{Result 3: Purposefulness increases average performance.}

\section{Discussion and potential implications for business organizations and public policy}

We began this paper by reviving a long-forgotten debate on incentives and prizes in the work of Cesare Beccaria and Giacinto Dragonetti. We now draw back our discussion to that early debate and, 
in particular, frame both type of rewards under a theory of human behavior developed by Dragonetti's master: The economist and philosopher Antonio Genovesi. Genovesi argued that human behavior depends on the interplay between two forces. On the one hand there is a centripetal force (forza concentriva) which leads individuals to self-directed actions, alienating them from their social relations; on the other hand, there is a centrifugal force (forza diffusiva) that pushes individuals to act for the common good to the extreme where they can be "detached from one self and annihilated" (Genovesi, 1776, p. 227). A virtuous, happy, and ethical life can be found by balancing these two opposite forces. Genovesi developed his dual-force concept of human behavior in contrast with Hobbes and Mandeville's political theories, which described human behavior as uniquely driven by the centripetal force. Individuals are fundamentally egoistic, and even when they entertain social interactions, they only do so in an instrumental manner. This reductionist approach to human behavior subsequently conflated into the utilitarian philosophy of Beccaria, Bentham, and basically all mainstream economists since Adam Smith (Porta, 2018). For Genovesi, instead, both forces are primitives of human nature (Bruni and Santori, 2018). Thus, Genovesi's dual-force distinction is useful to frame the two different approaches. According to Beccaria and modern economists, the world is full of incentives that feed the centripetal force to pursue self-serving goals; on the other hand, Dragonetti and Genovesi reminded us that for the equilibrium in organizations and social life to emerge, we need tools for supporting and strengthening the second force, the centrifugal one. The two forces require two different motivation toolboxes; this is the essence of our discourse that can have broad implications for organizations and policymaking.

Firms and other organizations that already make increasingly extensive use of incentives must pay attention to our results. Our experiment seems to suggest that prizes are more effective than incentives in building the feeling of community among people sharing certain internalized values and principles. In fact, unlike incentives, prizes act on people's intrinsic motivation, which allows them to interiorize norms and values that will be pursued even when prizes are excluded. In the language of moral philosophy, prizes recognize people's capital of virtues, and virtuous behavior is less 
dependent on individual cost-benefit analysis. Further work is needed to prove whether public prizes increase the team's reasoning or the we-rationality of groups (Sugden, 2003; Smerilli, 2012). It is plausible (and future experiments can explore this aspect) that the presence of prizes is more likely to create a we-frame in subjects as compared to incentives. Undoubtedly, there exist certain types of organizations that can do just fine by only relying on Genovesi's centripetal force, activated by means of incentives. However, most organizations, including many business and for-profit organizations, thrive only as long as their members - both managers and workers - also develop intrinsic values, such as loyalty, trust, a sense of belonging Freeman and Auster 2011; Auster and Freeman 2013; Freeman and Auster 2015). The message coming from the crowding-in effect of prizes should be of particular interest for communities, civil society organizations, associations, families, or those entities involved in fostering and spreading virtuous activities that require a certain degree of intrinsic motivation and the internalization of certain values (ecological, legal, pro-social behavior in general). Among all these organizations, our crowding-in result may be particularly interesting for the so-called value-based organizations (VBOs) (Bruni and Smerilli, 2014). Such organizations can be standard enterprises with a pro-social or merit mission, but also institutions that do not have a typical economic nature or goals — such as, for example, a political party, religious order, cultural or environmental association, trade union or NGO dedicated to the promotion of human or animal rights. VBO's are institutions inspired and held together by ideals and non-material motivations that interact with wages, profits, rewards, and market transactions as well. The purposefulness of task mission manipulated modeled in one of our experimental treatments captures this external, centrifugal element of VBOs. In VBOs, the motivational and relational dynamics must balance both self-serving centripetal and other-regarding centrifugal forces. These organizations work properly if the management is able to use motivational tools that also recognize and reward the ideal/symbolic forces that activate people and workers. In particular, the success of many VBOs revolves around a few core members - the founders and people with particular vocations who look after the VBO's specific activities - who are insensitive to incentives but may be much more responsive to prizes and other 
symbolic rewards. Moreover, using incentives to motivate core members is prone to fail, because such people are mainly activated by virtues and intrinsic motivation (centrifugal force). A take-home message of our experiment to VBOs is to increase the giving of prizes in their personnel policy, whereas currently, the tendency appears to go in the opposite direction.

The second implication of our results can be drawn with respect to organizational culture: A buzzword in management studies and particularly among large organizations. However, culture is about sincere, deeply rooted, non-instrumental, and non-manipulative values; it is about some habits and customs that are more profound and resilient than money or material rewards. At least some organizational character traits should be more robust than a sum of single reactions to incentives, which subsist even in areas not covered by incentivizing contracts. Our crowding-in effect suggests that the effects of prizes are resilient, and persist even when the reward is withdrawn. This result can significantly inform the growing debate on authenticity in organizations (Freeman and Auster 2011; Auster and Freeman 2013; Freeman and Auster 2015) inasmuch as authenticity requires the capacity, of both the organization and of its single members, to be intrinsically motivated by some shared core values that go well beyond instrumental motivations.

A third issue refers to the role of publicity. Our results showed that the publicity of the reward always increases performance. Civil society as well as churches, sports, scientific, and artistic communities use prizes and are aware of the positive role of publicity. However, publicity is less used among business organizations, which in turn make extensive use of standard incentives. In fact, the current business culture tends to "privatize" the relationship company/worker, considering the contract as a bilateral matter. ${ }^{12}$

\footnotetext{
${ }^{12}$ No systematic study has yet focused on the asymmetric adoption of publicity-based reward practices in for-profit companies and non-profit organization. Despite this gap in the literature, a comparative analysis of studies focusing on incentive/prize practices implemented in for-profit companies and non-profit organizations (see Oster, 1998; Luthans, 2000; Rodwell and Teo, 2004; Theuvsen, 2004; Opportunity Knocks, 2011; Ben-Ner et. al., 2011; Speckbacher, 2013; Ben-Ner and Ren, 2015; DeVaro et al. 2015; Gallus and Frey, 2016; Frey and Gallus, 2017a; Frey and Gallus, 2017b; WorldatWork, 2018a; WorldatWork, 2018b) leads to highly suggestive evidence. Monetary incentives are unanimously considered essential in business companies while public recognition represents a key element for staff retention in non-profit organizations.
} 


\section{Conclusions}

Modern organizations pervasively deploy complex systems of rewards and motivating tools, "a multitude of different mechanisms that can be used to induce workers to act in the interests of their employers" (Predergast, 1999, p.7). From the longtime use of "best employee of the month" business plates to the awarding of fringe benefits and the "gamification" of processes within firms (Robson et al., 2015), just to name a few. With respect to this complexity, the aim of this paper was twofold. The first was to counteract the growing trend of semantically reducing all forms of rewards to the narrow realm of incentives. The second was to disentangle prizes from incentives and to show how they motivate people differently. To make our case, we conducted an experiment that compared prizes and incentives along several dimensions, revealing that indeed the two types of rewards have different impacts on motivation. More specifically, our data results show that i) prizes crowd-in motivation to perform, even after the prize is removed; ii) the public dimension of the reward positively impact productivity; and iii) the purposeful mission of the task is important and helps to increase productivity. We argued that, among the various results, the crowding-in effect of prizes (result 1) is the main contribution of our experiment, which is significant also for its potential policy implications. We have shown that prizes have a persistent effect on motivation and performance and that this effect survives the withdrawal of prizes. However, this does not occur when incentives are at play. While we do not find a crowding-out effect of monetary incentives (this is consistent with a few previous findings of Ariely, 2009 and Kosfeld, Neckermann, and Yang, 2014, among others), we certainly find a crowding-in effect of prizes.

Experiments in business and economics must first and foremost be considered as means to falsify theories. As such, our experiment proves that the mainstream economics approach that coalesces all prizes into incentives and reduces the centrifugal force to a sophisticated version of the centripetal ones does not adequately account for the complexity of human motivation. Simultaneously, the simple, clean and abstract setting of the lab suggests being cautious in deriving 
direct and immediate implications for organizations and policymaking from our experimental findings. Further independent replication studies are needed in order to validate and complement our current findings (Camerer et al. 2016). Our main results can be interpreted as rhetorical arguments for initiating a reasoning. They are food for thought. In this spirit, we close our paper by offering a few suggestive interpretations of the results and of their operational implications.

\section{Acknowledgements:}

We thank the Editor Julie A. Nelson (Journal of Business Ethics), Jonathan Baron, Avner Ben-Ner, Anja Bodenschatz, Philip Brookins, Robert Dur, Christoph Engel, Marco Fabbri, Miloš Fišar, Ruth Grant, Werner Güth, Rainer Michael Rilke, Lorenzo Sacconi, Robert Sugden, Gari Walkowitz and two anonymous referees for their useful comments. We thank the participants at the 2016 U.I. Sophia Workshop in Economics and Management; the 2016 annual conference of the Italian Society of Law \& Economics; the 2017 "Pierluigi Porta" memorial workshop; the Behavioral and Experimental Economics Workshop at LUISS University for comments.

Financial support from the University of Cologne (DFG Research Unit FOR 1371 - Incentives in Firms: Compensation, Ethics, and Behavior), LUMSA University and the University of Cagliari is gratefully acknowledged.

\section{Disclaimer:}

The usual disclaimers apply. Experimental data are publicly available at the Open Science Framework (OSF) repository, project 〈osf.io/vzky2/> .

Revised version forthcoming in the Journal of Business Ethics. 


\section{References}

Adams, Orvill, Hicks, Vern. 2000. "Pay and non-pay incentives, performance and motivation,"4(3) Human Resources Development Journal," World Health Organization, Geneva.

Akerlof, George A. and Kranton, Rachel E. 2005. "Identity and the economics of organizations,"19(1) The Journal of Economic Perspectives 9--32.

Andreoni, James. 1990. "Impure altruism and donations to public goods: A theory of warm-glow giving,"100(401) The Economic Journal 464--477.

Ariely, D., Bracha, A., and Meier, S. 2009. "Doing good or doing well? Image motivation and monetary incentives in behaving prosocially,"99 American Economic Review 1--1.

Ariely, Dan, Kamenica, Emir, and Prelec, Drazen. 2008. "Man's search for meaning: The case of Legos," 67(3) Journal of Economic Behavior \& Organization 671--677.

Ashraf, Nava, and Oriana Bandiera. (2018) "Social incentives in organizations." Annual Review of Economics 10: 439-463.

Ashraf, Nava, Bandiera, Oriana, and Lee, Scott S. 2014. "Awards unbundled: Evidence from a natural field experiment,"100 Journal of Economic Behaviorl\& Organization 44--63.

Auster, Ellen R., and R. Edward Freeman. 2013. "Values and poetic organizations: Beyond value fit toward values through conversation." Journal of Business Ethics 113, 1: 39-49.

Baucus, Melissa S., and Caryn L. Beck-Dudley. 2005 "Designing ethical organizations: Avoiding the long-term negative effects of rewards and punishments." Journal of Business Ethics 56, 4: 355-370.

Beccaria, Cesare. 1764. On crimes and punishments.

Bellé, Nicola. 2015. "Performance-related pay and the crowding out of motivation in the public sector: A randomized field experiment,"75(2) Public Administration Review 230--241.

Ben-Ner, Avner, Ting Ren .2015. Comparing workplace organization design based on form of ownership: Nonprofit, for-profit, and local government. Nonprofit and Voluntary Sector Quarterly, 44(2), 340-359.

Ben-Ner, Avner, Ting Ren, and Darla Flint Paulson. 2011 "A sectoral comparison of wage levels and wage inequality in human services industries." Nonprofit and Voluntary Sector Quarterly 40, no. 4: 608-633.

Bénabou, Roland and Tirole, Jean. 2003. "Intrinsic and extrinsic motivation,"70(3) The Review of Economic Studies 489--520.

Bénabou, Roland and Tirole, Jean. 2006. "Incentives and prosocial behavior,"96(5) The American Economic Review 1652--1678.

Bénabou, Roland, and Jean Tirole. 2012. "Laws and norms”. IZA DP No. 6290

Blaise, Albert and Chirat, Henri. 1954. "Dictionnaire latin-francais des auteurs chrétiens: Revu spécialement pour le vocabulaire théologique," Le latin chrétien.

Bowles, Samuel and Polania-Reyes, S. 2012. "Economic incentives and social preferences: Substitutes or complements?"50(2) Journal of Economic Literature 368--425.

Bradler, Christiane, Dur, Robert, Neckermann, Susanne, and Non, Arjan. 2016. "Employee recognition and performance: A field experiment." 62(11) Management Science 3085-3099. 
Bruni, Luigino. 2013. "On virtues and awards: Giacinto Dragonetti and the tradition of economia civile in Enlightenment Italy," 35(04) Journal of the History of Economic Thought 517-535.

Bruni, Luigino. 2015. Incentives. In A Lexicon of Social Well-Being(pp. 72-75). Palgrave Pivot, London.

Bruni, Luigino, Paolo Santori, 2018: "The plural roots of rewards: awards and incentives in Aquinas and Genovesi", (Online first) The European Journal of the History of Economic Thought

Bruni, Luigino, Smerilli, Alessandra, 2014. The Economics of Values-Based Organizations: an Introduction, Oxford, Routledge.

Bruni, Luigino and Sugden, Robert. 2013. "Reclaiming virtue ethics for economics," 27(4) The Journal of Economic Perspectives 141--163.

Bruni, Luigino and Sugden, Robert. 2008. "Fraternity: Why the market need not be a morally free zone," 24(01) Economics and Philosophy 35--64.

Bruni, Luigino and Zamagni, Stefano. 2016. Civil economy: Another idea of the market. Newcastle upon Tyne: Agenda Publishing Limited.

Bruni, Luigino and Sugden, Robert. 2007. "The road not taken: How psychology was removed from economics, and how it might be brought back*," 117(516) The Economic Journal 146-173.

Bruni, Luigino and Sugden, Robert. 2000. "Moral canals: Trust and social capital in the work of Hume, Smith and Genovesi," 16(01) Economics and Philosophy 21--45.

Camerer, Colin F., Anna Dreber, Eskil Forsell, Teck-Hua Ho, Jürgen Huber, Magnus Johannesson, Michael Kirchler, et al. "Evaluating replicability of laboratory experiments in economics." Science 351, no. 6280 (2016): 1433-1436.

Chandler, Dana and Kapelner, Adam. 2013. "Breaking monotony with meaning: Motivation in crowdsourcing markets" 90 Journal of Economic Behavior \& Organization,123--133.

Charness, Gary, and Peter Kuhn. 2011. "Lab labor: What can labor economists learn from the lab?." Handbook of labor economics. Vol. 4. Elsevier, 229-330.

Cowen, Tyler and Tabarrok, Alex. 2015. Modern principles of microeconomics. Palgrave Macmillan.

Deci, Edward L. 1971. "Effects of externally mediated rewards on intrinsic motivation," 18(1) Journal of Personality and Social Psychology 105.

Deci, Edward and Ryan, Richard M. 1985. Intrinsic motivation and self-determination in human behavior, Springer.

Deci, Edward L. 1975. Intrinsic motivation. Plenum Press. Open library.

DeVaro, Jed, Maxwell, Nan. L., \& Morita, Hodaka. 2015. Compensation and Intrinsic Motivation in Nonprofit and For-Profit Organizations.

https://papers.ssrn.com/sol3/papers.cfm?abstract_id=2634880

Doerrenberg, Philipp and Duncan, Denvil. 2014. "Experimental evidence on the relationship between tax evasion opportunities and labor supply," 68 European Economic Review 48--70.

Dragonetti, Giacinto 1769. A treatise on virtues and rewards. Johnson and Payne, in Pater-NosterRow, and J. Almon, in Piccadilly.

Ellingsen, Tore and Johannesson, Magnus. 2007. "Paying respect," 21(4) The Journal of Economic Perspectives 135--149. 
Erkal, Nisvan, Gangadharan, Lata, and Koh, Boon Han. 2018. "Monetary and non-monetary incentives in real-effort tournaments,"101 European Economic Review 528--545.

Fabrizi, Michele, Christine Mallin, and Giovanna Michelon. 2014. "The role of CEO's personal incentives in driving corporate social responsibility." Journal of Business Ethics 124, 2: 311-326.

Falk, Armin. 2007. "Gift exchange in the field," 75(5) Econometrica 1501--1511.

Festré, Agnes and Garrouste, Pierre. 2015. "Theory and evidence in psychology and economics about motivation crowding out: A possible convergence?" 29(2) Journal of Economic Surveys 339--356.

Fischbacher, Urs. 2007. "z-Tree: Zurich toolbox for ready-made economic experiments," 10(2) Experimental Economics 171-178.

Freeman, R. Edward, and Ellen R. Auster. 2011. "Values, authenticity, and responsible leadership." Journal Business Ethics 98:15-23

Freeman, R. Edward, and Ellen R. Auster. 2015. Bridging the values gap: How authentic organizations bring values to life. Berrett-Koehler Publishers, Oakland, CA.

Frey, Bruno S. and Oberholzer-Gee, Felix. 1997. "The cost of price incentives: An empirical analysis of motivation crowding-out," 87(4). The American Economic Review 746-755.

Frey, Bruno S. and Jegen, Reto. 2001. "Motivation crowding theory," 15(5) Journal of Economic Surveys 589--611.

Frey, Bruno S. 2006. "Giving and receiving awards," 1(4) Perspectives on Psychological Science 377--388.

Frey, Bruno S. 2007. "Awards as compensation," 4(1) European Management Review 6--14.

Frey, Bruno S. and Gallus, Jana. 2017a. "Towards an economics of awards," 31(1) Journal of Economic Surveys 190--200.

Frey, Bruno S., and Jana Gallus. 2017b Honours versus money: The economics of awards. Oxford University

Frye, Harrison P. 2017. "Incentives, offers, and community," 33(3) Economics and Philosophy 367_390

Gallus, Jana., \& Frey, Bruno S.. 2016. “Awards as non-monetary incentives”. In Evidence-based

HRM: a Global Forum for Empirical Scholarship (Vol. 4, No. 1, pp. 81-91). Emerald Group Publishing Limited.

Genovesi, Antonio. 1776. La logica per gli giovanetti. Stamperia Reale. Naples.

Genovesi, Antonio. 1835. Della diceosina o sia della filosofia del giusto e dell'onesto. Società tipografica de' classici italiani. Milan.

Georges Karl, Ernst. 1998. Ausführliches lateinisch-deutsches Handwörterbuch.. Unchanged reprint of the eighth improved and increased edition, , 2 volumes, Darmstadt: Scientific book company, 1998 (reprint of the Hannover edition: Hahnsche bookstore, 1913/1918).

Gill, David and Prowse, Victoria L. 2011. "A novel computerized real effort task based on sliders," IZA Discussion Paper No. 5801. Available at SSRN: https://ssrn.com/abstract=1877614

Gneezy, Uri, Meier, Stephan, and Rey-Biel, Pedro. 2011. "When and why incentives (don't) work to modify behavior," 25(4) The Journal of Economic Perspectives 191--209.

Gneezy, Uri and Rustichini, Aldo. 2000a. "Pay Enough or Don't Pay at All,"115(3) Quarterly Journal of Economics 791-810. 
Gneezy, Uri and Rustichini, Aldo. 2000b. "A Fine is a Price,"29(1) Journal of Legal Studies 1-17.

Grant, Ruth W. 2011. Strings attached: Untangling the ethics of incentives. Princeton University Press.

Grant, Ruth W. 2019. "Incentives and Praise Compared: the Ethics of Motivation," International Review of Economics

Greiner, Ben. 2015. "Subject pool recruitment procedures: Organizing experiments with ORSEE," 1(1) Journal of the Economic Science Association 114--125.

Ims, Knut J., Lars Jacob Tynes Pedersen, and Laszlo Zsolnai. 2014. "How economic incentives may destroy social, ecological and existential values: The case of executive compensation." Journal of Business Ethics 123, 2: 353-360.

Jensen, Michal, Murphy, Kevin. 1990. "Performance pay and top-management incentives”. 98(2) Journal of Political Economy 225--264.

Kahneman, Daniel J., Knetsch, Jack L., and Thaler, Richard H. 1990. "Experimental tests of the endowment effect and the Coase Theorem," 98(6) Journal of Political Economy 1325-1348.

Kosfeld, Michael, Neckermann, Susanne, and Yang, Xiaolan. 2014. "Knowing that you matter, matters! The interplay of meaning, monetary incentives, and worker recognition," IZA Discussion Paper, No. 8055.

Kube, Sebastian, Maréchal, Michel André, and Puppea, Clemens. 2012. "The currency of reciprocity: Gift exchange in the workplace,"102(4) The American Economic Review 1644--1662.

Kulshreshtha, Praveen. 2005 "Business ethics versus economic incentives: Contemporary issues and dilemmas." Journal of Business Ethics 60, 4: 393-410.

Kurland, Nancy B. (1995) "Ethics, incentives, and conflicts of interest: A practical solution." Journal of Business Ethics 14, no. : 465-475.

Lacetera, Nicola and Macis, Mario. 2010. "Social image concerns and prosocial behavior: Field evidence from a nonlinear incentive scheme,"76(2) Journal of Economic Behavior \& Organization 225 - 237.

Laffont, Jean-Jacques and Martimort, David. 2002. The Theory of Incentives. The Principal - Agent Model, Princeton and Oxford : Princeton University Press.

Levitt, Steven D. and Dubner, Stephen J. 2006. Freakonomics: A rogue economist explores the hidden side of everything, Harper Collins.

Luthans, Kyle. 2000. Recognition: A powerful, but often overlooked, leadership tool to improve employee performance. Journal of Leadership Studies, 7(1), 31-39.

Manno, Giuseppe. 1831. Della fortuna delle parole, Turin: Fratelli Pomba.

Mirrlees, James. 1999. "The Theory of Moral Hazard and Unobservable Behaviour: Part I," Review of Economic Studies, 66(1) 3--21

Maréchal, Michel André and Thöni, Christian. 2016. "Hidden persuaders: Do small gifts lubricate business negotiations?" University of Zurich, Department of Economics, Working Paper No. 227. Available at SSRN: https://ssrn.com/abstract $=2775290$

Mathauer, Inke and Imhoff, Ingo. 2006. "Health worker motivation in Africa: The role of nonfinancial incentives and human resource management tools," 4(1) Human Resources for Health 24. 
McAdams, Richard H. 2015. The expressive powers of law: Theories and limits. Harvard University Press, 2015.

McGuire, Jean, Sandra Dow, and Kamal Argheyd. 2003. "CEO incentives and corporate social performance." Journal of Business Ethics 45, 4: 341-359.

Mickel, Amy E. and Barron, Lisa A. 2008. "Getting 'more bang for the buck' symbolic value of monetary rewards in organizations,"17(4) Journal of Management Inquiry 329--338.

Moldovanu, Benny, Sela, Aner, and Shi, Xianwen. 2007. "Contests for status," 115(2) Journal of Political Economy 338--363.

Neckermann, Susanne and Frey, Bruno S. 2013. "And the winner is...? The motivating power of employee awards," 46 The Journal of Socio-Economics 66--77.

Nadler, Janice. 2017 "Expressive law, social norms, and social groups." Law \& Social Inquiry 42, 1: 60-75.

OpportunityKnocks. 2011, Engagingthe Nonproft Workforce: Mission, Management and Emotion. Technical report

Oster, Sharon .1998. Executive compensation in the nonprofit sector. Nonprofit Management and Leadership, 8(3), 207-221.

Pianigiani, Ottorino. 1990. Dizionario etimologico della lingua italiana, I Dioscuri.

Porta, Pier Luigi. 2018. "From Economia Civile to Kameralwissenschaften. The line of descent from Genovesi to Beccaria in pre-Smithian Europe." (Online first) The European Journal of the History of Economic Thought .

Prendergast, Canice. 1999. "The Provision of Incentives in Firms," 37(1) Journal of Economic Literature 7-63.

Read, Daniel. 2005. "Monetary incentives, what are they good for?"12(2) Journal of Economic Methodology 265--276.

Rodwell, John., \& Teo, Stephen. 2004. Strategic HRM in for-profit and non-profit organizations in a knowledge-intensive industry: The same issues predict performance for both types of organization. Public Management Review, 6(3), 311-331.

Sandel, Michael J. 2012. What money can't buy: the moral limits of markets, Macmillan.

Shoaib, Shandana, and Yehuda Baruch. 2017. "Deviant Behavior in a Moderated-Mediation Framework of Incentives, Organizational Justice Perception, and Reward Expectancy." Journal of Business Ethics 140, 1: 1-17.

Smerilli, Alessandra. 2012. "We-thinking and vacillation between frames: Filling a gap in Bacharach's theory," 73(4) Theory and Decision 539--560.

Speckbacher, Gerhard. 2013. The use of incentives in nonprofit organizations. Nonprofit and Voluntary Sector Quarterly, 42(5), 1006-1025.

Sugden, Robert. 2003. "The logic of team reasoning,"6(3) Philosophical explorations 165--181.

Sugden, R., 2019. "Awards, incentives and mutual benefit". 66(1) International Review of Economics, 5-17.

Sunstein, Cass. (1996) "On the Expressive Function of Law," University of Pennsylvania Law Review, 144(5), 2021-2053.

Titmuss, Richard Morris. 1970. The gift relationship. From human blood to social policy. Allen \& Unwin Ltd., London. 
Tonin, Mirco and Vlassopoulos, Michael. 2013. "Experimental evidence of self-image concerns as motivation for giving," 90 Journal of Economic Behavior \& Organization 19--27.

Theuvsen, Ludwig. 2004. Doing better while doing good: Motivational aspects of pay-forperformance effectiveness in nonprofit organizations. Voluntas: International Journal of Voluntary and Nonprofit Organizations, 15(2), 117-136.

Ward, M.K. and Broniarczyk, S.M., 2011. "It's not me, it's you: How gift giving creates giver identity threat as a function of social closeness". Journal of Consumer Research, 38(1), pp.164-181

Weiss, Yoram and Fershtman, Chaim. 1998. "Social status and economic performance: A survey," 42(3) European Economic Review 801--820.

WorldatWork . 2018a. Incentive Pay Practices: Nonprofit/Government Organizations. Technical report

WorldatWork .2018b. Incentive Pay Practices: Privately Held Companies. Technical report 


\section{MUNI Econ Working Paper Series (since 2018)}

2019-04 Bruni, L., Pelligra, V., Reggiani, T., Rizzolli, M. (2019). The Pied Piper: Prizes, Incentives, and Motivation Crowding-in. MUNI ECON Working Paper n. 2019-04. Brno: Masaryk University. https://doi.org/10.5817/WP_MUNI_ECON_2019-04

2019-03 Krčál, O., Staněk, R., Karlínová, B., Peer, S. 2019. Real consequences matters: why hypothetical biases in the valuation of time persist even in controlled lab experiments. MUNI ECON Working Paper n. 2019-03. Brno: Masaryk University. https://doi.org/10.5817/WP_MUNI_ECON_2019-03

2019-02 Corazzini, L., Cotton, C., Reggiani, T., 2019. Delegation And Coordination With Multiple Threshold Public Goods: Experimental Evidence. MUNI ECON Working Paper n. 2019-02. Brno: Masaryk University. https://doi.org/10.5817/WP_MUNI_ECON_2019-02

2019-01 Fišar, M., Krčál, O., Staněk, R., Špalek, J. 2019. The Effects of Staff-rotation in Public Administration on the Decision to Bribe or be Bribed. MUNI ECON Working Paper n. 2019-01. Brno: Masaryk University. https://doi.org/10.5817/WP_MUNI_ECON_2019-01

2018-02 Guzi, M., Kahanec, M. 2018. Income Inequality and the Size of Government: A Causal Analysis. MUNI ECON Working Paper n. 2018-02. Brno: Masaryk University. https://doi.org/10.5817/WP_MUNI_ECON_2018-02

2018-01 Geraci, A., Nardotto, M., Reggiani, T., Sabatini, F. 2018. Broadband Internet and Social Capital. MUNI ECON Working Paper n. 2018-01. Brno: Masaryk University. https://doi.org/10.5817/WP_MUNI_ECON_2018-01

ISSN electronic edition 2571-130X

MUNI ECON Working Paper Series is indexed in RePEc:

https://ideas.repec.org/s/mub/wpaper.html 